\title{
FUSION AND EVALUATION OF 3D DATA AND EXCAVATION DOCUMENTS FOR COMPARISON OF ORIGINAL AND DIGITAL COPY IN THE CASE OF A MEGALITHIC TOMB
}

\author{
F. Russell ${ }^{1}$, P. Kalinowski ${ }^{2}$, F. Both ${ }^{1}$, T. Luhmann ${ }^{2}$, U. Warnke ${ }^{1}$ \\ ${ }^{1}$ Landesmuseum Natur und Mensch (State Museum Nature and Man) Oldenburg, Damm 38-46, 26135 Oldenburg, Germany, \\ (f.russell, f.both, u.warnke)@landesmuseen-ol.de \\ 2 Jade University of Applied Sciences, Institute of Applied Photogrammetry and Geoinformatics (IAPG), Ofener Str.16/19, 26121 \\ Oldenburg, Germany, (paul.kalinowski, luhmann)@jade-hs.de
}

KEY WORDS: Authenticity, Data Fusion, Modeling, Photogrammetry, 3D Reconstruction, Archaeology, Megalithic Tomb, Heritage Management.

\begin{abstract}
:
This contribution shows the preliminary results of the multidisciplinary cooperation of archaeological, technical and heritage issues using the example of the megalithic tomb Kleinenkneten II. The tomb was excavated in the 1930s, but big parts of the documentation have unfortunately been destroyed. Furthermore, some ancient interpretations need to be objectively reviewed. More than 500 historical image data visually document the historical excavation situation. In addition, the current situation was recorded in 3D using modern methods. Geodetic products, such as orthophotos, can be derived from modern data and compared with old plans. Also, a point cloud was calculated from historical images, which can be compared with the current situation. The combination of modern and historical data enables new archaeological interpretations. From a museum perspective, strategies for the construction of authentic value of the $3 \mathrm{D}$ model is considered, as well as its communication to the public.
\end{abstract}

\section{INTRODUCTION}

\subsection{Motivation}

This paper reports on preliminary results of a research project which was initiated in order to ensure the safekeeping of valuable archaeological knowledge through digitisation. The threat of decay through the passage of time is a constant threat in heritage management. In several case studies from the collection of the Landesmuseum Natur und Mensch Oldenburg, Germany, in a cooperation with the Jade University of Applied Sciences Oldenburg, the research project presented here aims to examine how digital archiving and visualisation tools can promote the preservation and presentation of sensitive cultural heritage objects. The central case study deals with the digital reconstruction of the excavation of the two large stone tombs of Kleinenkneten, Oldenburg district, in north-western Germany (Michaelsen, 1975/76). The site was excavated during the 1930s by leading local archaeologists and museum staff of today's Landesmuseum Natur und Mensch Oldenburg in order to examine their supposedly use as "Germanic cult halls" (Halle 2014). A particular challenge in the tracing of the excavation process lies in the precarious source situation. Most of the documentation was lost when the Oldenburg State Library was bombed during World War II. Only a few hundred historical glass pictures and photo negatives, as well as some excavation plans are still available today (example in Figure 3). The digitisation of these long overlooked and delicate source materials should not only help in tracing the excavations, but also guarantee the survival of the information for future generations of researchers.

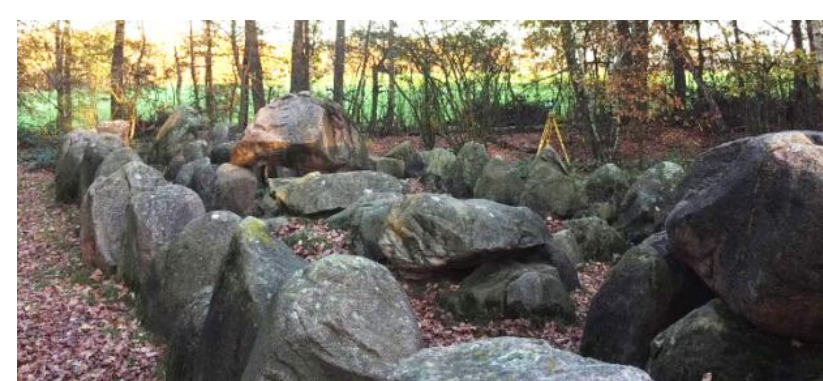

Fig. 1: Megalithic tomb Kleinenkneten II.

\subsection{Archaeological State of Knowledge}

The grave complex Kleinenkneten II is extraordinarily valuable due to its state of preservation (Figure 1). The megalithic tomb has a total of three burial chambers in its enclosure and dates from the Neolithic period from about 3600 to 2800 B.C. The excavations took place in the 1930s under the direction of the present-day Landesmuseum Natur und Mensch (Both, Warnke 2020). The 34-metre long enclosure remains almost completely preserved. The former six-bay burial chamber in the eastern part of the complex still has all the supporting stones in their original position, but only two of the capstones have survived. The entrance to the chambers is on the south-east side. The southwestern burial chamber with opposite access is an exception. The middle burial chamber was not known or visible before the excavations began. It was only rediscovered during the excavations. Several burial chambers in an enclosure of a large stone tomb are otherwise rarely found in northern Germany. There has always been the assumption that the middle burial chamber is younger and was inserted later between the graves that were possibly surrounded by oval enclosures. This is supported by the fact that the enclosure in the central area does not run in a straight line, but is slightly constricted. A new analysis of the find material, especially of the pottery finds, in the context of an ongoing dissertation project by N. Delsmann, 
University of Groningen (the Netherlands), could perhaps reveal a time difference here.

\subsection{Research Questions and Structure}

The research project combines different perspectives on the challenges and chances of digitization from the field of applied sciences, archaeology, and heritage studies. As a consequence, the research questions posed and examined are diverse but can only be answered in interdisciplinary collaboration (Figure 2). Besides retracing the decisions and finds made during the 1930s excavation, the digital model of Kleinenkneten II will also help to elucidate separate phases of usages by locating and contextualizing the unearthed objects. And how did the direct environment of the site change over time? The issue of change also raises the question of authenticity. How can the case of Kleinenkneten II illustrate the historical development of perceptions of authenticity in the field of archaeology and its current, digital renegotiation?

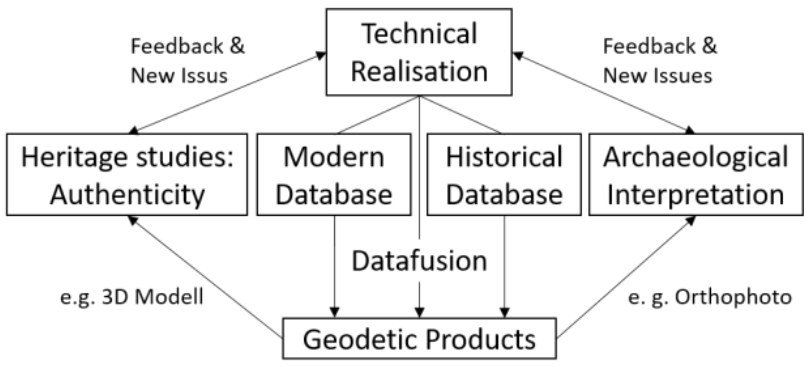

Figure 2: Interdisciplinary cooperation to produce and evaluate technical products for archaeological interpretations and heritage studies.

This paper will provide a concise overview over the initial data situation, the challenges faced, and the steps undertaken in digitizing the megalithic site. It will then present the preliminary archaeological conclusions drawn from the newly created data sets, concluding with a brief discussion of the potential state of authenticity of digital objects.

\section{DATABASE}

The data basis for the interdisciplinary research project consists of historical photographs and film footage on the one hand and a 3D model of the current situation recorded using modern measuring technology on the other.

\subsection{Historical Database}

Fortunately, not all the historical data was destroyed by the previously mentioned bomb hit. In total, the following image data shown in Figure 3 are available and can be examined and interpreted using modern methods:

- 7 aerial images (A)

- 1 historical film record (B)

- Approx. historical 400 photographs (C)

- $\quad$ Approx. 100 glass plate negatives (D)

- Few historical plans (E)
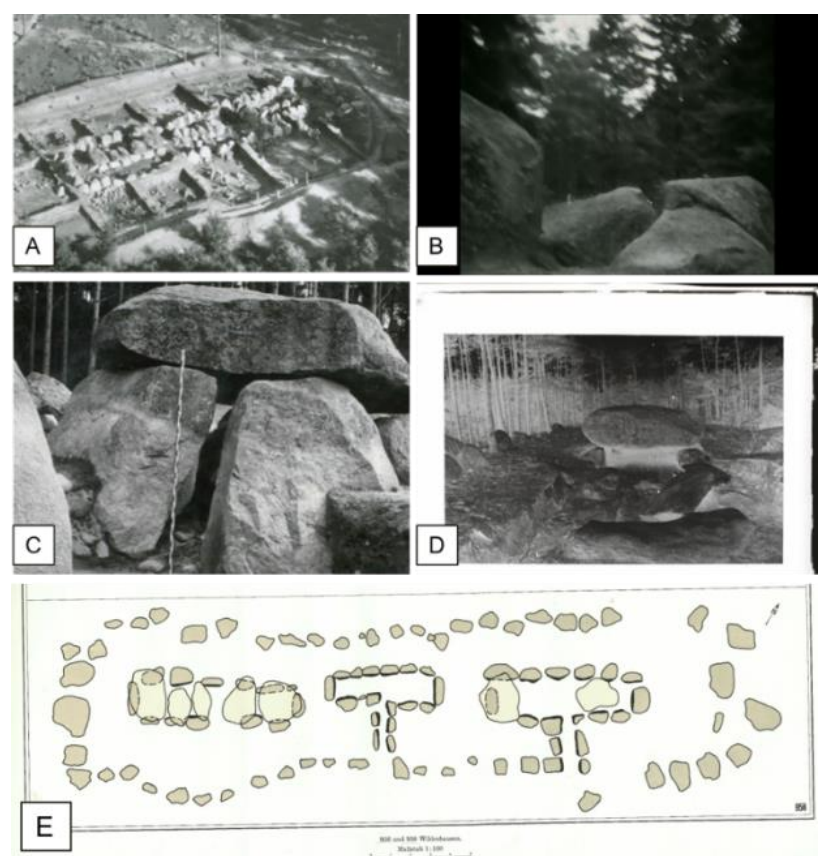

Figure 3: Historical aerial image (a), historical film record (b), historical photograph (c), historical glass plate negative (d), historical plan (e).

While the quality of the aerial photographs and the film recording is low, the overall quality of the photographs and glass plates is very high. The images are predominantly sharp and have good contrast. Only a few images are underexposed or overexposed. All historical data are available in digitised form for further processing.

Despite the overall high quality of the individual image data, there are some challenges for photogrammetric investigations. These are often given with historical image data:

- $\quad$ Radiometric differences

- Different image scales

- Different image formats

- No information about the historical camera

- Insufficient overlap across the entire scene

The image data were not taken according to photogrammetric standards. Most of the time, the photographer rotated around his own axis or took pictures of individual areas of the scene.

Although a high number of images is given, there is insufficient overlap across the entire scene. A 3D object reconstruction is therefore not possible for the entire excavation situation Furthermore, an archaeological excavation is considered as a temporal process. Photographs depicting the same scene show different progress of the excavation.

In summary, such a high number of historical images depicting the same scene is rather unusual. Due to the high quality of many images, the potential for investigations with both modern methods and modern data in combination is considered high.

\subsection{Modern Database}

In order to represent the current situation of the stone grave as a digital model, the open grave chamber of Kleinenkneten II has been recorded. For the $3 \mathrm{D}$ reconstruction, terrestrial laser scanning, close-range photogrammetry and UAV were combined, as demonstrated by (Luhmann et al., 2019) for 
complex churches. Data fusion, evaluation and modelling was conducted with the SfM software Reality Capture (Version 1.1.1).

Figure 6 shows the 3D model including all camera orientations and laser scan viewpoints. The mean reprojection error (Sigma 0) is 0.6 pixels. For further processing, the model was reduced from 663 to 24 million triangles and a resolution of $5 \mathrm{~mm}$ in order to achieve faster processing times.

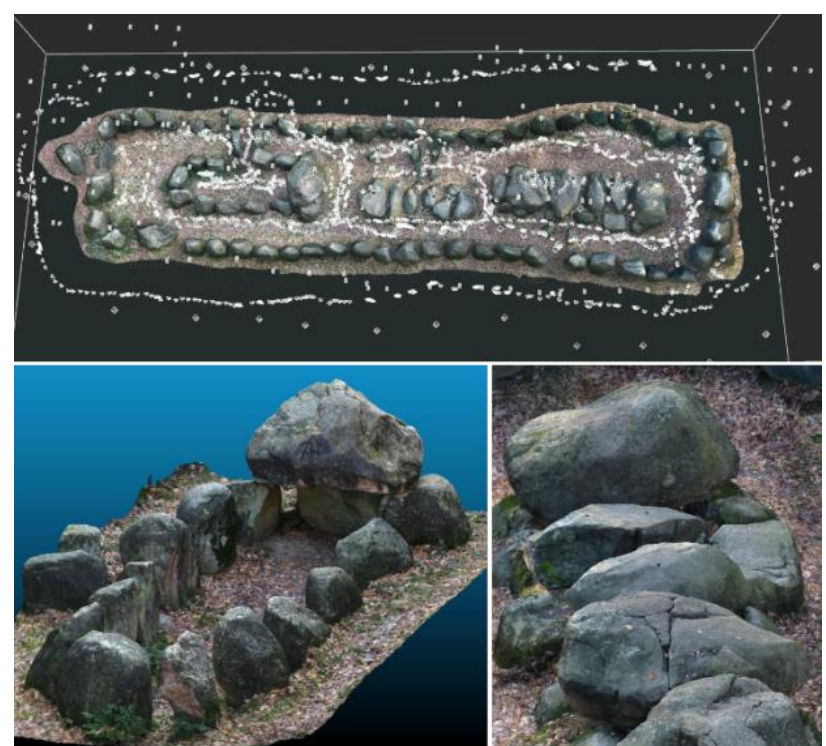

Figure 4: TLS, terrestrial images and UAV orientations (top), detailed view of the calculated mesh (bottom).

Due to the large amount of data, the megalithic tombs could be completely represented as a textured 3D model. Even though the texture is influenced by shadows cast by the surrounding trees, the calculated mesh in Figure 4, bottom right, can also be interpreted as a photograph. For this reason and because of the high level of detail and completeness, the model is well suited for museum use.

\section{DATA FUSION AND DERIVED OUTPUT}

For archaeological and heritage investigations, the historical and modern data are combined. The aim is to reconstruct the historical excavation process in order to be able to assess it objectively. Furthermore, both the historical and the modern data offer the possibility to derive different photogrammetric products. The technical realisation, especially the possibilities for merging historical images with the 3D model, is described in detail in Kalinowski et al. 2021. Here, the focus is on the interpretation of the data.

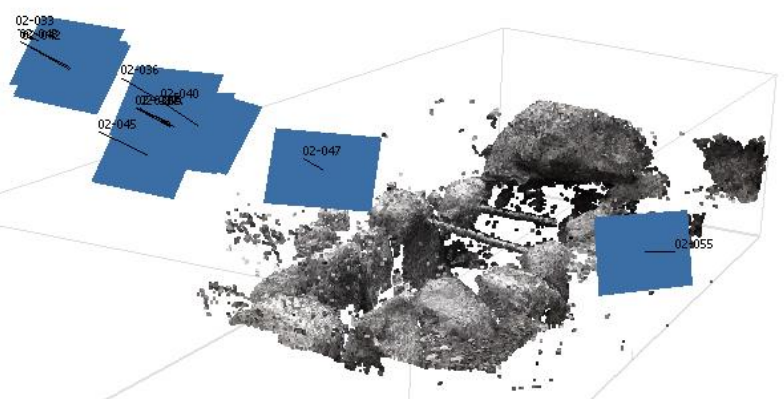

Figure 5: Modell calculated by SfM with historical images.
Some areas can be reconstructed in 3D using the historical images if there is sufficient overlap. Figure 5 shows a 3D model of chamber 2 calculated from 12 historical images using the SfM software Agisoft Metashape. In combination with the modern 3D model, the historical situation of the chamber can be compared with the situation today. Figure 6 shows the comparison between the mesh of the modern model and the point cloud from historical images.

For this area of the tomb it becomes clear that the present situation has hardly been changed compared to the historical excavation. Most stones deviate from each other in the range of -5 $\mathrm{cm}$ to $+5 \mathrm{~cm}$. Only a few stones have changed by $25 \mathrm{~cm}$ (blue and red). This is probably due to subsidence or erosion. It is remarkable that even the capstone corresponds to the position of the excavation.

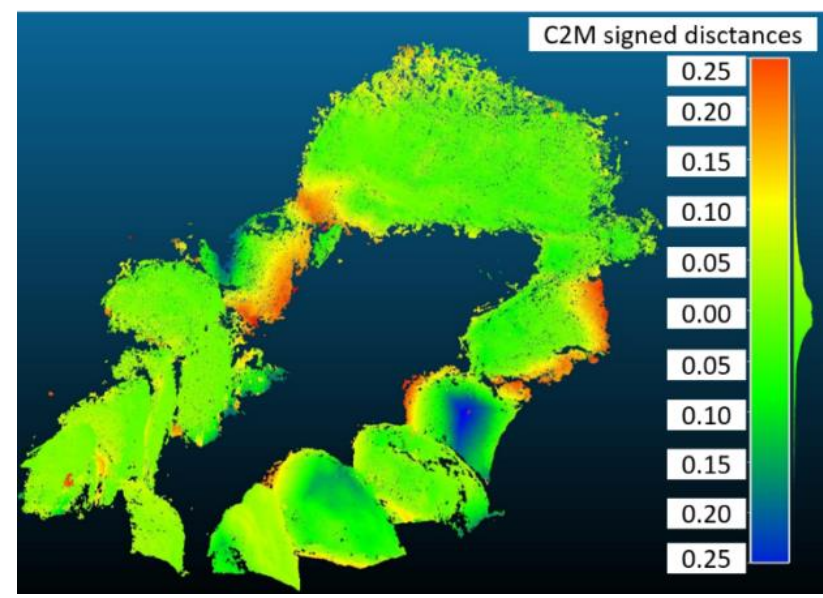

Figure 6: Comparison between modern mesh and point cloud from historical images in $\mathrm{m}$.

Furthermore, the current 3D model offers the possibility for known geodetic products, e.g. true orthophotos. Figure 7 shows the manual overlay of a historical plan with a true orthophoto. In this case, the entrance stones (marked in yellow) are clearly visible on the orthophoto but they are not included in the historical plan. The modern data thus make it possible to examine objectively the historical plans and to uncover and visualise inaccuracies or errors.

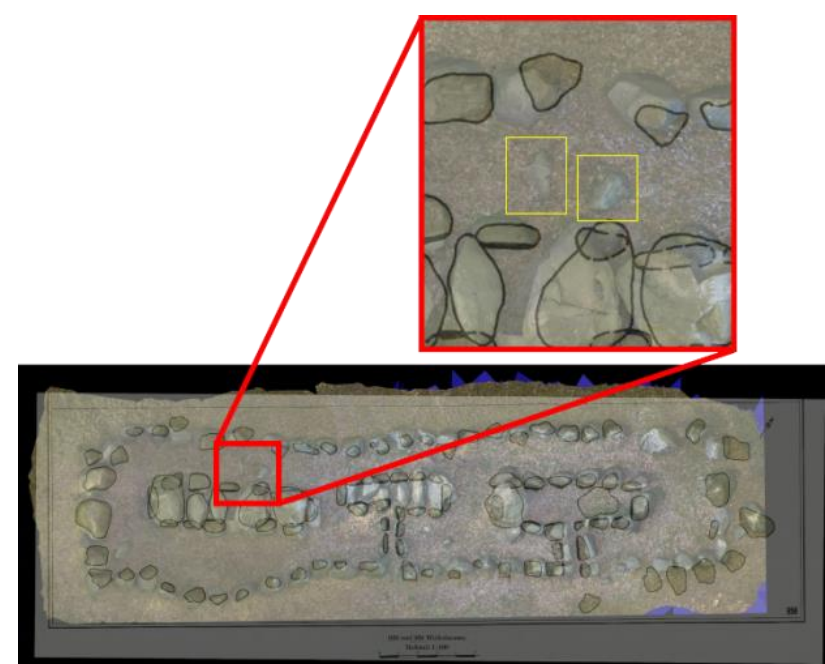

Figure 7: Graphic superimposition of recent true orthophoto with historical excavation plan (bottom). Missing stones in historical plan highlighted in yellow, visible in true orthophoto. 


\section{ARCHAEOLOGICAL EVALUATION}

An early excavation plan of Kleinenkneten II was published before the excavations began, followed by a site plan in 1937 (Figure 3), which showed the entire complex after it had been excavated. This plan served as a basis for subsequent visualizations. However, it failed to depict significant details like the entrance area in the south-west chamber, although the stones of the entrance can be seen on the excavation photos (Figure 8).
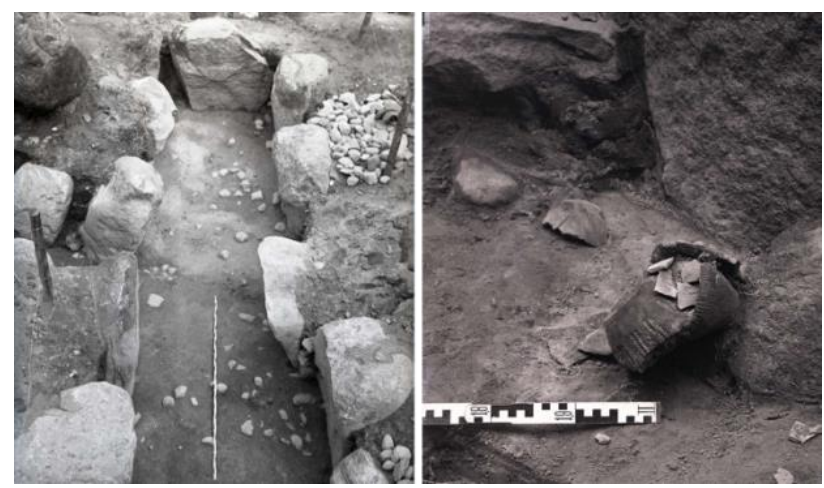

Figure 8: Burial chamber 1, view of support stone 3 and the threshold stone of the entrance (left); sherds of a total of three vessels pressed into each other in Burial chamber 2.

In addition, a so-called threshold stone was found in the entrance area there. Did the excavators omit the stones because the contemporary research status defined the opposite side of the tomb as traditional entry point? These and other questions can be pursued with today's 3D digitisation and provide new insights for the interpretation of the excavation findings. With the help of 3D models, in addition to the digitised two-dimensional images of the excavation documentation, the contemporary site interpretation is to be virtually re-evaluated. Against the background of current archaeological research, it will be possible to take a new look at find and deposit contexts. What activities took place in the burial chamber over the centuries? Which ones in the entrance area and in the outer area? Were there distinguishable phases of use? The burial chambers of Kleinenkneten II were sunk into artificial horizons. In the process, partial cobbles and pottery finds came to light again and again (Figure 8, right).

\section{CHALLENGES OF DIGITAL AUTHENTICITY}

In addition, the project deals with the questions of how technology influences our interpretation of cultural heritage. The existence of the photographic recordings hereby offers the opportunity to discuss the relationship between newly emerging technologies and archaeological work.

\subsection{Mutability}

When photography first gained popularity about 180 years ago, it was heralded for its supposed objectivity through the removal of human interference in the scientific fact-finding endeavour. Throughout the course of the $19^{\text {th }}$ century, it slowly but steadily succeeded more traditional forms of presenting archaeological finds, like illustrations. By the early $20^{\text {th }}$ century then, archaeology had grown into a full-fledged scientific discipline with its own rules and standards, with photographic technology as core visualisation tool (Garstki, 2017). Similarly, 3D modelling and highly detailed measurement methods have opened up a wide range of visualization and interpretation options for archaeological projects, seemingly getting closer and closer to an absolute level of detail. However, this scientific strive for objectivity and exactitude in the field also carries the risk applying technology without the critical reflection on the influence of the researcher's motives and definition of what is authentic or 'true' (Ibid.). Additionally, technical innovations can be anxiety-inducing and are often seen in opposition or in competition with more traditional tools (Witcomb, 2007). Most recent 3D reconstruction projects praise the mutability of digital models as an essential characteristic that lifts the possibilities of scientific research above those of physical models. Only if a reconstruction can be adapted according to new findings and theories, and if, importantly, those steps in the research process are properly recorded, archaeological work can live up to its full scientific potential (Lulof, 2020, Warnke, in preparation, 2021). But what effect does the mutability of digital objects have on the notion of authenticity? The aspect of alteration or changing of the material conditions of cultural heritage has been an issue in the field of archaeology already before the rise of digital technology. For instance, conservation experts have to find the right balance between ensuring the survival of cultural heritage objects and, at the same time, fulfilling visitor expectations of what a historic object should look like. In the case of stone monuments such as Kleinenkneten II, changes in the appearance of the material due to processes of decay caused by nature's impact or human usage are often considered as visual evidence of a site's age and, therefore, authentic value (Douglas-Jones et al., 2016).

This inherent dilemma of conservation work to allow an object to change and to carry signs of this temporal change on its surface while all too drastic human interference is interpreted as a threat to authenticity is also transferred to digital objects. But contrary to their material counterparts, digitised cultural heritage objects are not subject to environmentally caused decay. Signs of age can be transferred from the reference object but after this initial moment of digital creation, this patina will remain unchanged. At the same time, potentially far-reaching adjustments can be made with a simple click of a mouse. So how is it possible to create authentic value for such digital objects?

\subsection{Originality}

At the core of this issue lies the original-copy dichotomy. But recently, researchers have suggested that this differentiation ignores the intricate interplay of digital as well as physical copies with their environment. It could be argued, for example, that the involvement of stakeholders in the selection and production of digitisation projects can help for the results to be perceived as authentic. Participation represents an arguably more powerful tool to integrate digital objects into a public's cultural memory and practice than for example high-definition resolution. So when it comes to 3D objects and their authenticity, the focus of research should lie less on the minute representation and visualisation but on building and highlighting relationships between human stakeholders and digital heritage (Jones et al., 2018).

For an institution like the museum, which draws a large part of its own status from its collection of originals (Cameron and Robinson, 2007), the digitization of objects and their presentation signifies an existential challenge. Museum history has shown that the use of copies has been continuously re-evaluated, depending on the contemporary understanding of originality or authenticity and its significance for visitor education (Hochreiter, 1994). In the case of Kleinenkneten II, such issues play a central role, especially concerning the presentation of the project results within the museum space and on-site. Relating to the observations made by Jones et al. (2018), this would require the open communication of the creation process of the $3 \mathrm{D}$ model of Kleinenkneten II. By describing and explaining the decisions 
made within the involved stakeholders on how to digitise the site and what motivations drove the initiative, the resulting model could be understood as a consequence of scientific work and standards. At the same time, however, this kind of information will also help to imbue the digital model with authentic value. After all, the development of a $3 \mathrm{D}$ visualisation is not only a process of production driven by technology and science but also by human creativity, ingenuity and collaboration. In this way the model of Kleinenkneten II will serve as an exemplification of how the availability and active communication of digisitation data can combat notions of 'artificiality' (Douglas-Jones et al., 2016) among visitors and other stakeholders and construct a new form of authenticity.

\section{SUMMARY AND OUTLOOK}

In this paper, the multidisciplinary work of archaeology, photogrammetry and museum approach was presented on the example of the megalithic tomb Kleinenkneten II. The base for the investigation is given by historical image data and a modern 3D model of the current situation. By combining the historical and modern data, new products can be generated to objectively (re)interpret the historical excavation. A comparison between a point cloud, calculated from historical images, and the modern 3D model shows marginal changes for burial chamber 2 . In this area, it can be assumed that the spatial situation of this area was not changed during the excavation or afterwards. By overlaying an old plan and a modern orthophoto, it can be objectively confirmed that stones exist at the entrance, which were not previously mentioned in historical documentation.

Furthermore, the challenges for museum work with 3D models in terms of authenticity are discussed. One of the central concerns examined is the question how the resulting models can be imbued with authentic value and can, therefore, be experienced as significant cultural heritage in their own right. It is argued that a highly detailed visualisation is less decisive, but instead, the involvement of stakeholders in the digitisation and the presentation of the process as a creative activity has the potential to enable valorisation.

In the future, further geodetic products are to be derived by combining the historical and modern data. This requires a close cooperation between the archaeological and technical disciplines. The aim is to reconstruct the historical excavation situation to enable new archaeological interpretation. The authenticity of the modern 3D model when used in a museum context will continue to be investigated by cultural studies.

\section{ACKNOWLEDGEMENTS}

This work is based on the "MoDi" project, funded by the Volkswagen Foundation (ZN3496).

\section{REFERENCES}

Both, F., Warnke, U., 2020: Digitalisierung im Museum. Das Fallbeispiel der Großsteingräber von Kleinenkneten. museums:zeit, Mitteilungsblatt N.F. 76, 47-48.

Cameron, F., Robinson, H., 2007: Digital Knowledgescapes: Cultural, Theoretical, Practical, and Usage Issues Facing Museum Collection Databases in a Digital Epoch. In F. Cameron and S. Kenderdine, Theorizing Digital Cultural Heritage: A Critical Discourse. MIT Press, Cambridge, London, 165-191.

Douglas-Jones, R., Hughes, J. J., Jones, S., Yarrow, T., 2016: Science, value and material decay in the conservation of historic environments. Journal of Cultural Heritage 21, 823-833. doi.org/10.1016/j.culher.2016.03.007.

Garstki, K., 2017: Virtual Representation: the Production of 3D Digital Artifacts. Journal of Archaeological Method and Theory 24, 3, 726-750. doi.org/10.1007/s10816-016-9285-z.

Halle, U., 2014: Graben für Germanien: Wie Großsteingräber zu germanischen Kulthallen wurden. Wildeshausener Schriften für Heimat, Geschichte \& Kultur 12, 56-75.

Hochreiter, W., 1994: Vom Museumstempel zum Lernort: Zur Sozialgeschichte Deutscher Museen 1800-1914. Wissenschaftliche Buchgesellschaft, Darmstadt.

Jones, S., Jeffrey, S., Maxwell, M., Hale, A., Jones, C., 2018: 3D heritage visualization and the negotiation of authenticity: the ACCORD project. International Journal of Heritage Studies 24, 4, 333-353. doi.org/10.1080/13527258.2017.1378905.

Kalinowski, P., Both, F., Luhmann, T., Warnke, U., 2021: Data Fusion of Historical Photographs with Modern 3D Data for an Archaeological Excavation - Concept and First Results. ISPRS Congress 2021, Nice, accepted for publication.

Luhmann, T., Chizhova, M., Gorkovchuk, D., Hastedt, H., Chachava, N., Lekveishvili, N., 2019: Combination of terrestrial laserscanning, UAV and close-range photogrammetry for $3 \mathrm{D}$ reconstruction of complex churches in Georgia. Int. Arch. Photogramm. Remote Sens. Spatial Inf. Sci., XLII-2/W11, 753761. doi.org/10.5194/isprs-archives-XLII-2-W11-753-2019.

Lulof, P., 2020: Recreating Reconstructions: Archaeology, Architecture and 3D Technologies. In S. Dupré, A. Harris, J. Kirsell, P. Lulof, M. Stols-Witlox, Reconstruction, Replication and Re-enactment in the Humanities and Social Sciences, Amsterdam University Press, Amsterdam, 253-274.

Michaelsen, K., 1975/76: Die Ausgrabung der beiden Hünenbetten von Kleinenkneten in Oldenburg 1934-1939. Oldenburger Jahrbuch 75/76, 215-249.

Warnke, U., in preparation, 2021: Stichwort Bergung und Befund. In M. Sabrow and A. Saupe, Handbuch Historische Authentizität, Wallstein, Göttingen.

Witcomb, A., 2007: The Materiality of Virtual Technologies: A New Approach to Thinking about the Impact of Multimedia in Museums. In F. Cameron and S. Kenderdine. Theorizing Digital Cultural Heritage: A Critical Discourse. MIT Press, Cambridge, London, 35-48. 